\section{Apuntes metodológicos para la creación de un archivo digital sobre la fotografía del conflicto armado en Colombia 2002-2006}

\section{Resumen}

La fotorreportería del conflicto armado en Colombia entre 20022006 constituye una investigación concomitante al desarrollo de un proyecto de tesis doctoral. Este artículo se circunscribe a la metodología de esa primera investigación preliminar en cuanto base de una fuente primaria y estudio de esa fotorreportería del rotativo EI Tiempo de Bogotá. De ahí que el volumen de ese archivo constituya hoy un repositorio visual del conflicto armado en Colombia de estimado valor para el Centro de Documentación en Imagen y Diseño de la Universidad de Caldas, Manizales, Colombia.
John Wilson Herrera Murcia Ph.D. en Diseño y Creación Docente Universidad Autónoma de Occidente

Cali, Colombia

Correo electrónico: johnwilsonherrera@

gmail.com

(1) orcid.org/0000-0002-5729-229X

Google Scholar

Aurelio A. Horta Mesa

Ph.D. en Ciencias sobre Arte

Profesor Titular de la Universidad Nacional de Colombia sede Bogotá

Bogotá, Colombia

Correo electrónico: aahortam@unal.edu.co

응 orcid.org/0000-0003-2132-9908

Google Scholar

Adriana Gómez Alzate

Ph.D. en Sostenibilidad, Tecnología y

Humanismo

Docente Universidad de Caldas

Manizales, Colombia

Correo electrónico: adriana.gomez@

ucaldas.edu.co

ำ orcid.org/0000-0001-5279-041X

Google Scholar

Liliana María Villescas Guzmán Magíster en Diseño y Creación Interactiva Docente Universidad de Caldas

Manizales, Colombia

Correo electrónico: liliana.villescas@

ucaldas.edu.co

(1) orcid.org/0000-0003-1145-7682

Google Scholar

Recibido: Octubre 30 de 2017

Aprobado: Agosto 31 de 2018

Palabras clave:

Archivo, diseño, fotorreportería, imagen, conflicto armado, memoria.

Revista KEPES Año 16 No. 19 enero-junio 2019, págs. 183-216 ISSN: 1794-7111(Impreso) ISSN: 2462-8115 (En línea) DOI: 10.17151/kepes.2019.16.19.8 


\section{Methodological notes for the creation of a digital archive on photography of the armed conflict in Colombia 2002-2006}

\begin{abstract}
The photo story of the armed conflict in Colombia between 2002 and 2006 constitutes a concomitant research into the development of a doctoral thesis project. This article is confined to the presentation of the methodology carried out in that first preliminary research based on a primary source and the study of that photo story in El Tiempo newspaper of Bogotá. Hence, the volume of that archive constitutes a Visual Repository of the Armed Conflict in Colombia of an intangible value for the Image and Design Documentation Center attached to the Department of Visual Design at Universidad de Caldas.
\end{abstract}

Key words:

Archive, design, photo journal,

image, armed conflict, memory. 


\section{Introducción}

Lo que necesitamos es una crítica de la cultura visual que permanezca alerta ante el poder de las imágenes para bien y para mal, capaz de discriminar entre la variedad y especificidad histórica de sus usos. (Mitchell, 2009, p. 10)

El presente artículo se propone presentar, y asimismo dar cuenta, del por qué de una doble investigación: de una investigación concomitante, como resulta el propósito de esta publicación, derivada de la tesis doctoral "Estudio de la fotorreportería del conflicto armado en Colombia entre 2002 y 2006: archivo, imagen y enunciación".

La razón de este archivo digital preliminar se justifica por constituir las fuentes primarias de la investigación de grado ya enunciada que propició el reconocimiento del volumen, tramitología de acceso y preparación tecnológica previa que requería la revisión de ediciones del periódico El Tiempo en los cinco años que corren entre 2002-2006. Se hizo ineludible el montaje de una investigación paralela al proyecto del problema central a modo que la primera facilitara el manejo que exigía el estudio sobre esta fotorreportería, definitivamente significante más allá del dato en un documento de primer orden. A propósito, Didi-Huberman (2004) en su ejemplar memoria visual sobre el holocausto reflexionó al respecto,

no vemos por qué un pedazo de realidad - el documento de archivo- convocaría de forma tan inevitable el <mentís > de lo real. No vemos por qué el hecho de interrogar una imagen de archivo equivaldría tan mecánicamente a una negativa a escuchar <la palabra humana>. Interrogar una imagen no es sólo cuestión de una <pulsión escópica>, como pretende Lanzmann: es necesario el cruce constante de los acontecimientos, de las palabras, de los textos. (p. 142)

Para el filósofo e historiador francés — como más tarde se continuó estimando por otros autores - el valor especulativo sobre la imagen infiere, complementa, a veces también decide, la confiabilidad de un dato; de ahí que esta clase de 
imagen producto de la guerra, constituya un documento de valor. Con una mayor atención cuando, como en este caso, se conoce extraída de una noticia dada por una publicación periódica; asunto delicado que reclama un detallado trato de intervención, toda vez que se trata de una fotografía con fines de una amplia comunicación social; más aún, de una ilustración infausta como fue ese largo período del conflicto armado con las guerrillas pertenecientes a las Fuerzas Armadas Revolucionarias de Colombia (FARC). Igualmente esta imagen fotorreportera grabó en la consciencia social, con o sin condicionamiento, una opinión de sucesos que irremediablemente impactaron una sociedad y un país; cuya recepción, si bien comunicó, igual descolocó y extravió para cualquier ojo agudo como el de un investigador las pesquisas o argumentos de sus indicios retóricos y visuales absolutamente lejanos e impensables de una imagen que dispone un fragmento único de la realidad. Entonces el objetivo nuclear de esta investigación, a priori descansó en un estudio analítico con intención hermenéutica de esa representación fotográfica compleja; en primera instancia por ese carácter de trance de operaciones que esta constata entre el hecho en sí, la oportunidad de la fotografía, su edición y recepción de lectura'.

Ciertamente la fotorreportería no acepta la pertinencia de un específico marco teórico del arte, aunque esta de natural produce una imagen que ilustra visionando o aludiendo —en este caso, algo supuestamente real- . Sin embargo su concreción no es artística, aún con una fuerte carga estética. De ahí que la modulación descriptiva de su estudio requiera de un proceso que va de su estructura, espacio comprendido, formas y atmósfera a la búsqueda de un carácter que concluye mostrando desde un punto de vista de acto fotográfico una postura de riesgo, un gesto con latencia de sentidos varios y una captación

\footnotetext{
${ }^{1}$ Un pasaje del discurso de Didi-Huberman (2004), en el capítulo 7, del libro ya referenciado, aduce que: "todo acto de imagen es arrancado de la imposible descripción de una realidad. Los artistas, en particular, se niegan a someterse a lo irrepresentable cuya experiencia vaciadora conoce bien-como cualquiera que haya afrontado la destrucción del hombre por el hombre. Entonces, realizan series, montajes pese a todo: también saben que los desastres son multiplicables hasta el infinito. Callot, Goya o Picasso — pero también Miró, Fautrier, Strzeminski o Gerhard Richter- trituraron lo irrepresentable en todos los sentidos para que dejase escapar algo más que puro silencio" (p. 185).
} 
de imagen con un alto dominio técnico que da fe de un profesionalismo singular; nada casual ni rebuscado, llámese de una aprehensión estética conscientemente diferida ${ }^{2}$.

Por otra parte este tipo de fotografía reportera dada su autonomía estética evidencia una autopoiesis caracterizada por su principio de organización y las relaciones modales que establecen las formas, espacios, y el acto experimental de una fotografía que por su misma verosimilitud demanda de una efectividad de las circunstancias que representa; al igual que de la búsqueda de ese vacío no representado de lo cruel y aparencialmente increíble que el filtro regular de una lente de cámara fotorreportera fue capaz de anticipar ${ }^{3}$. Una captación hipotética de la realidad que se aproxima a la episteme de un acto de diseño, sin que este se desvincule ni demerite el talento creativo del reportero ya manifiesto en el dominio de entrever la congruencia entre el espacio tiempo de la imagen y la realidad sugerida a la par de una imaginación activa.

Por su parte esta investigación con el propósito de la configuración de un banco de fotorreporetería de guerra excedió sus fines expuestos, por lo que se entendió debía constituir un fondo de consulta y referencialidad digital a favor de esa probable consulta que un sinnúmero de problemas de la investigación sociocultural, del arte y el diseño visual precisan.

\footnotetext{
${ }^{2}$ Una observación que no se puede dejar atrás en el caso de la fotorreportería justamente se debe a que no siempre —en el caso particular del conflicto armado en Colombia- esta reportería cuando de estragos de batalla o combate se trata se realiza en un tiempo posterior en ocasiones no distante, pero no posible en ese mismo momento del evento, por lo que resulta una imagen diferida que todavía sorprende por su poder de reproducir la magnitud de lo sucedido. Podría convenirse que mucho le debe al campo de la antropología visual, a una etnografía de los restos. Consúltese sobre este campo, entre otros estudios, a Colombres (2012).

${ }^{3}$ Acerca del tema de los modos en las objetividades estéticas, véase a Claramonte (2016); que desde el criterio de quienes suscriben, resulta un importante aporte al campo de las relaciones modales desde lo estético.
} 


\section{Nociones, proceso y herramientas de una metodología}

El levantamiento del corpus de la fotorreportería en cuestión se basó en tres núcleos de clasificación categorial desde referentes teóricos de diversos autores y áreas de conocimientos. En relación con los estudios sociales se consideraron los aportes de Teófilo Vásquez (2015), William Ospina (1995) y Carlos Sixirei (2012). En atención a las teorías de la imagen y la estética se tuvieron en cuenta aquellos estudios de mayor empoderamiento y alcance para el análisis del objeto mismo de la investigación; privilegiándose la teoría del valor axiológica de Stefan Morawski (1999), la teoría del diseño de Aurelio Horta (2012) y las teorías de la imagen de Philippe Dubois (1986), W.J.T. Mitchell (2009) y Pepe Baeza (2007).

En consonancia con la archivística y los procesos de memoria que en ello subyace se aproximaron las perspectivas teórico críticas de Carmen María Jaramillo (2010), Andrea Giunta (2010) y André Porto Ancona López (2011) entre otros autores que fundamentan presupuestos y constructos metodológicos de reflexión potencialmente útiles en el caso de análisis e interpretación de la fotorreportería. Cuestión está a la que se suma una reflexión no menos dispendiosa acerca de las posibles circunstancias que suelen apremiar las políticas editoriales en el caso específico de El Tiempo. En este sentido se estructuró un prototipo de archivo según las categorías enunciativas de las diferentes realidades que las mismas imágenes fotográficas ofrecían del conflicto, las cuales se listan en la siguiente tabla. 
Herrera, J.W. Horta, A. Gómez, A. Villescas, L. / Apuntes metodológicos para la creación de un archivo digital sobre la fotografía del conflicto armado en Colombia 2002-2006

Tabla 1. Categorías de análisis del conflicto armado en su delimitación nacional 2002-2006.

\begin{tabular}{|c|c|c|c|}
\hline & $\begin{array}{l}\text { Número de imágenes } \\
\text { del conflicto armado }\end{array}$ & $\begin{array}{c}\text { Suma de } \\
\text { categorías }\end{array}$ & $\begin{array}{l}\text { Categorías } \\
\text { con más } \\
\text { representación }\end{array}$ \\
\hline 1. Apoyo o movilización social & 83 & & \\
\hline 2. Asesinatos-magnicidio-genocidio & 70 & & \\
\hline 3. Atentados-emboscadas-bombas-ataques & 267 & & 2 \\
\hline \multirow[t]{2}{*}{ 4. Barbarie de la guerra } & 197 & $\begin{array}{c}\text { Suma de } 4.1,4.2 \\
4.3,4.4,4.5\end{array}$ & 3 \\
\hline & $\begin{array}{l}\text { 4.1. Falsos positivos } 7 \\
\text { 4.2. Fosas comunes } 17 \\
\text { 4.3. Masacres } 104 \\
\text { 4.4. Minas } 22 \\
\text { 4.5. Otras anomalías } 48\end{array}$ & & \\
\hline 5. Capturas-detenciones & 148 & & 5 \\
\hline 6. Combates-enfrentamientos & 97 & & \\
\hline 7. Desaparición forzada & 10 & & \\
\hline 8. Desplazamiento forzado-destierro-éxodo & 65 & & \\
\hline 9. Estrategias de la guerra & 882 & $\begin{array}{c}\text { Suma de } 9.1,9.2 \\
9.3,9.4\end{array}$ & 1 \\
\hline
\end{tabular}

9.1. Desmovilizados-reinsertados-desertores 166

9.2. Fuerzas del Estado 195

9.3. Fuerzas insurgentes (ELN-FARC-paramilitares) 153

(12-26-115)

9.4. Políticas y fuerzas de Estado 368

\begin{tabular}{lcl}
\hline 10. Narco-drogas & 141 & 4 \\
\hline 11. Problema territorio-frontera & 164 & \\
\hline 12. Reclutamiento infantil & 22 & \\
\hline 13. Secuestros-retenidos-liberaciones & 146 & \\
\hline 14. Violencia indígena & 8 & \\
\hline Anexo. Retratos actores de la guerra & 92 \\
\hline Total de imágenes & 2392 \\
\hline
\end{tabular}

Fuente: elaboración propia por parte de los autores. 
Estos complexos de sentido que enunciaban las categorías del conflicto se constituyeron en recurso de método del archivo fotorreportero digital que se definió denominar "Repositorio Visual del Conflicto Armado en Colombia", archivo optimizado para la Web bajo la autoridad y custodia de la Imagoteca o Centro de Documentación en Imagen y Diseño adscrita al Departamento de Diseño Visual de la Universidad de Caldas ${ }^{4}$. El término repositorio se deriva del latín repositorium ('armario', 'alacena'). En este caso ha de ser entendido como departamento de depósito y reserva para la visualización, consulta e información del tema que se aborda. Si apelamos a la definición que plantea la RAE, es el lugar donde se guarda algo. Este espacio digital catalogado y conceptualizado representa un aporte documental de excepción acerca de un fragmento del conflicto armado en Colombia, así como una fuente histórica de memoria en línea.

En cuanto al archivo repositorio se establecen dos grandes áreas: (i) el conflicto armado en Colombia y (ii) el conflicto armado internacional. Asimismo, este particular remitió a la consideración de dos anexos que integran la investigación central pero que constituyen fondo del repositorio: (i) retratos actores de la guerra y (ii) contexto histórico de conflictos armados y guerras en Colombia y el mundo.

La base teórico-conceptual que fundamentó ambas investigaciones se centró en una relación modal —entiéndase de método- entre el análisis de la fotografía del conflicto como primer filtro de optimización visual, que de hecho exigió de referencias de diferentes campos de conocimiento, y la correspondiente a la historia social de Colombia; a lo que indiscutiblemente se sumó la historia de su fotografía, de sus manifestaciones culturales de incidencia, y las recursivas de la estética y teorías del arte y el diseño para cerrar un nodo de análisis e interpretación.

${ }^{4}$ Unidad de información especializada en diseño e imagen, creada en 1995 en el Departamento de Diseño Visual de la Universidad de Caldas; en donde reposa la Muestra Monográfica de Media Art del Festival Internacional de la Imagen (http://festivaldelaimagen.com/). 
El procesamiento de las imágenes para su catalogación, a partir de un orden cronológico, fue la elaboración de su etiquetación; es decir el inventariar y nombrar las imágenes en relación con la fecha, el titular de la noticia de procedencia, la nota pie de foto original, la región del acontecimiento y con estos datos las palabras clave que las identifican. Este proceso por sí solo demandó de una cuidadosa atención por cuanto urgió de una visión técnica desde lo fotográfico, pero por su razón de ilustrar en una investigación de una interpretación coherente y efectiva. De manera que el archivo visual cuenta con un manejo de uso ágil para los investigadores interesados. Además se describieron sus características formales con el propósito de una posterior indexación, según las categorías y el lenguaje pertinente para una comunidad internacional en los tesauros.

Este banco y/o repositorio visual en tanto documento medular y episódico, así como por su importancia, prescribió un discurso de ese entramado del conflicto más allá del territorio agreste y áspero rural; revelando otras conexiones donde la ciudad y actores de muy distintos intereses toman parte. En este sentido fue indispensable apropiarse de alguna norma que por encima del marco estructural de análisis velara por principios estéticos más generales, que no obviaran en ningún momento una máxima de esa imagen fotográfica: su potencial estético y su capacidad de enunciación. Esas consideraciones resueltas en invariantes metodológicas se muestran en la siguiente tabla. 
Tabla 2. Invariantes metodológicas de la investigación.

\begin{tabular}{|c|c|}
\hline \multicolumn{2}{|c|}{ Lineamiento metodológico } \\
\hline \multirow[b]{2}{*}{ Consideraciones tácticas } & Invariantes metodológicas \\
\hline & Valor estético (representación) de la imagen fotorreportera \\
\hline \multirow[t]{2}{*}{$\begin{array}{l}\text { Búsqueda, selección y creación de la imagen } \\
\text { fotorreportera }\end{array}$} & $\begin{array}{c}\text { Valor estético (significado) del diseño visual en la } \\
\text { fotorreportería }\end{array}$ \\
\hline & Valor estético (enunciación) de la fotografía reporteril \\
\hline
\end{tabular}

Fuente: elaboración propia por parte de los autores.

Esa estimación especial acerca de lo estético a partir de los valores de representación, significado y enunciación afianzó un aspecto primordial que podía subestimarse dada la energía emocional de la fotografía como es la retórica de su enunciado ${ }^{5}$.

La colección de fotografías alcanzó finalmente la cifra de 8465 imágenes cuando el archivo primario de 2392 se procesó teniendo en cuenta las exigencias de edición que la investigación de tesis demandaba de cinco fases o modos de examinar y visualizar cada una de las fotografías. Estas variables de revisión fueron las siguientes: (i) la fotografía del periódico tal cual su publicación. Es decir la página completa del periódico donde está la noticia y el contexto de la misma; (ii) la fotografía con su pie de foto; (iii) la fotografía con su encuadre original de impresión, que difiere del encuadre original de captura reiteradamente; (iv) la fotografía (close-up) en el plano de página completa del rotativo, a modo de aproximar al consultor o lector a la inscripción dada por la editorial en relación con otras noticias para contrastar su relevancia respecto del conflicto armado en sí; (v) por último, un gráfico visual a manera de mapa del sitio de los acontecimientos.

${ }^{5}$ Esa importancia que suele restar o añadir la potencia de la imagen a su enunciación, o sea a su representación de la fotografía, afirma la inflexión lingüística de Benveniste (1999) cuando apunta que "el hombre no dispone de ningún otro medio de vivir el 'ahora' más que realizarlo por inserción del discurso en el mundo" (p.86). 
Estos modos o métodos de acción con las imágenes respondieron a diferentes etapas de análisis teórico, consultas y búsqueda de fuentes orientadas a una deconstrucción técnica entre imágenes, tablas, esquemas y bocetos con el interés de definir un orden enunciativo. De este modo se establecieron seis etapas o fases de trabajo. La primera etapa inicio con una adecuación de condicionantes que necesitaba la colección de imágenes en las que se consideraron parámetros técnicos para la captura del material impreso. Por ejemplo, una cámara profesional de óptica intercambiable (lentes 18-70 mm, $70-210 \mathrm{~mm}$ y macro $60 \mathrm{~mm}$ ), las propiedades del uso del espacio físico (lugar) destinado para la captura entre las que dominaba el aspecto de la iluminación artificial del mismo; estos últimos de gran complejidad debido a que se debía prever la interacción con otros investigadores en un espacio reducido para el registro de las fuentes, así como por las condiciones de luz alógena que poseía el sitio en relación con los balances de luz y las sombras proyectadas sobre el material gráfico impreso; a esto se sumaban las condiciones de almacenamiento digital, carga y descarga del material a la par de las características del formato de captura inicialmente definido como RAW y posteriormente como JPG de acuerdo con el peso de almacenamiento de cada imagen y del archivo en su totalidad. Todos estos aspectos enmarcaron esta primera etapa significativa de la calidad del material recolectado.

En la segunda etapa se clasificó el material en dos grandes áreas y dos campos de relación, a saber: el conflicto armado en Colombia 2002-2006, dominio de interés de la investigación en cuanto estado de un contexto nacional y por lo tanto de su repercusión en las políticas y leyes del país; y al unísono el correspondiente a las conexiones internacionales en ese mismo período, encabezado por aquellos eventos nacionales de guerra con implicación internacional que de una u otra manera modelaban e interferían en el plano geopolítico. Para los segundos hubo que diferenciar procesos muy diferentes de acuerdo a sus causales como fueron los particulares accidentes en Colombia, en contrapunto con las guerras y conflictos 
en otros Estados o Naciones y las instancias de organismos internacionales comprometidos tales como la Organización de los Estados Americanos (OEA), la Organización de las Naciones Unidas (ONU), la Corte Penal Internacional (CPI), la Corte Interamericana de Derechos Humanos (CIDH), el Banco Mundial (BM), el Congreso de los Estados Unidos, la UNESCO, la Fundación para la Libertad de Prensa (FLIP) entre otras. Este tejido de circunstancias, factos de guerra y sus autores contó de igual modo con un capítulo digital de imágenes sustantivo de los retratos de actores del contexto histórico de los conflictos armados y guerras en Colombia y el mundo.

A lo anterior se suma otro tipo de publicación de artículos y fotografías acerca de confrontaciones bélicas de la Primera y Segunda Guerra Mundial, así como del siglo pasado en relación con el Oriente Árabe, que ilustran históricamente muchos de los acontecimientos y actores vinculados a la temporalidad de este estudio; es decir los archivos de prensa encontrados entre 2002-2006, que aludían a rastros históricos de guerra que aportaban una visión de generalidad sobre las visiones de la guerra en Colombia.

La tercera fase o etapa del proceso dependió de un grueso material de importancia para la investigación que reclamó de una especificación aún más concreta: la clasificación de los archivos en relación con las diferentes escalas características del conflicto. Teniendo en cuenta su ampliación de márgenes se trató de sintetizar, lo más posible, su naturaleza de coincidencia o no con vista a no omitir ninguno de estos procesos; de ahí que se dirimiera en principio un filtro marco por encima de los sucesos a partir del concepto 'guerra' o "conflicto armado" de manera que se pudiera individualizar una batalla frontal, de lo que son las secuelas de esta, e identificar sus acciones conexas.

Si bien estas variantes de procedimiento agregaban al problema investigativo un orden de perplejidad, lo cierto es que esta decisión se verificó cuando la escritura 
comenzó a demandar del análisis y descripción del evento una introspección más justificativa del criterio. Este fue uno de los aportes concluyente del por qué de la creación del repositorio y de la importancia que tenía el mismo para la academia, en particular para la Universidad de Caldas teniendo en su haber una investigación acerca del evento más determinante y crudo del país en toda su historia. Esta fotorreportería, desde su carácter de imagen congelada en una noticia periódica, enunciaba un texto de memoria visual de indiscutible valor cultural que ha de entenderse como una penosa y sufrida realidad del país. Al respecto, de esta clase de imagen, Santos Zunzunegui (1995) plantea que "la foto ya no pertenece al orden del icono [semejanza] ni al del símbolo [representación por convención cultural], sino al orden del índex que se define por la contigüidad física del signo con su referente" (p. 140).

Esta precisión cognitiva lo visual, de Zunzunegui, reasume el signo imagen fotográfica como unidad indivisible entre lo real y lo representado; afirmando la fuerza con que la misma es definida, en este caso como una fotorreportería, abstrayendo en su síntesis un modo distintivo de observación y relaciones que en dirección con la guerra reclama siempre una interrogación por cuanto establece esa extrañeza y distancia con aquello que representa lo sustancial de una existencia.

En la cuarta etapa, valga aclarar, las unidades documentales de la fotorreportería constituyen en sí mismas delimitaciones que viabilizan la interpretación y reflexión crítica por cuenta de las categorías que las ubican conceptualmente; aunque al mismo tiempo este ordenamiento y contrastación con otras imágenes, según se ha apuntado, declinan y estimulan otro acoplamiento como es el de reconocer el listado suma de estas imágenes fotográficas en atención a su particular fotorreportero (es decir, por autores de las imágenes). Punto de vista que ubica la proximidad del fotógrafo con la humanidad de la guerra, su postura e ingenio profesional, en relación con un contexto. Un rango de 
análisis concluyente en cuanto permite identificar en una matriz de valores y análisis la relevancia de los actos fotográficos en relación con el número de imágenes y la actuación de los fotorreporteros ${ }^{6}$. En suma, esta sistematización particular y general que pauta la metodología abre opciones y visiones de cómo se está leyendo e interpretando esa realidad.

De aquí se deduce cuáles son las características técnicas de calidad de estas imágenes, también su frecuencia de edición y sus autores con vista a una optimización para la Web; si bien las imágenes originales se archivan en una carpeta ad hoc para proteger el material primario. Todas las imágenes optimizadas se circunscriben a características específicas para su visibilidad en pantallas full screen tanto de computadoras como de dispositivos móviles con las siguientes indicaciones. Estas serían sus configuraciones técnicas: fotografía página completa del periódico (1024 píxel de ancho x largo); fotografía del conflicto con pie de foto (768 píxel de alto x ancho); fotografía en su encuadre original de impresión (768 píxel de alto $\mathrm{x}$ ancho); mapas (768 píxel de alto $\mathrm{x}$ ancho); detalles (close-up) relevantes de algunas páginas (768 píxel de alto x ancho).

La intervención y tratamiento con el archivo visual de imágenes catalogadas y subordinadas define el proceso de la quinta etapa de la metodología. Se reitera que estas imágenes conforman tres tipos de archivo: el de la página completa del periódico; el de la foto con el pie de foto y el de la foto en su encuadre original de impresión. El texto que acompaña la fotografía (pie de foto) debió ser transcrito y anclado a la imagen como caption (campo para escribir) con el propósito de que los buscadores que indexen la información rastreen la imagen codificada por etiquetas (fecha, titular, pie de foto, ubicación geográfica por

\footnotetext{
" Fíjese cómo no sería posible en la especificidad de esta enunciación referirse a un "acto de creación" porque significaría un acto artístico; en este caso, esa imagen fotorreportera resulta en un acto de fotorreportería; una acción que crea una imagen, pero donde el proceso y el resultado no son de expectación sublime ni de ilusión o contemplación sino de una aptitud de reconstrucción de un escenario que exige de precisión con un objetivo concreto de informar "tal suceso"; trátese de un acto de diseño.
} 
departamento y palabras o nombres clave). Para los buscadores, la imagen no dice nada; es el texto el que da contexto a la imagen, permitiendo su ubicación y discriminación en la Web. Esta delimitación se establece en procura de que los investigadores que necesiten hacer búsqueda por algún criterio puedan hallar la información de toda la colección vinculada a la respectiva etiqueta.

Las directrices de uso del sitio se implementaron en un manual, hoja de ruta para el posterior ingreso de otras temporalidades asociadas al estudio de la fotorreportería o colecciones de otra índole sobre conflictos y guerras en el mundo. Y es la Imagoteca (Centro de Documentación en Imagen y Diseño) de la Universidad de Caldas, la cual realiza uso de los protocolos para permitir el ingreso de investigadores y del público autorizado al material.

Justo, una sexta etapa del proceso metodológico orienta el diseño de esa plataforma para lograr una navegación intuitiva al tiempo que proyecta parámetros de lectura y legibilidad óptimos para su acceso. La plataforma alberga, organiza y clasifica la información en dirección a un diseño específico con contenido de 8465 archivos. Si consideramos las implicaciones para el acceso a la información de prensa diaria y la pérdida de calidad que ostentan los microfilmados, sin contar el deterioro que ya presenta el periódico impreso dada la calidad del papel en que históricamente se imprime, podemos advertir que la captura fotográfica levantada por el investigador principal constituye un ejercicio de muy alta complejidad y valor en cuanto las diversas etapas que se debieron superar para lograr una optimización y visibilidad del archivo de imágenes.

Esta construcción por etapas del repositorio visual sobre el conflicto armado en Colombia resultó una apuesta por ampliar otro espectro posible de actualización y revitalización de la memoria respecto de un espacio y temporalidad específicos de cuatro años de consternación, frustraciones y desarraigos de una época 
ojalá innombrable nunca más. En efecto, esta memoria visual documental del repositorio que funda esta fotografía únicamente asume su valor en cuanto sea visitado y consultado. En palabras de Philippe Dubois (1986) "a través de la simple observación de las fotografías, el espectador puede desmontar la fabricación de la obra" (p. 13); es decir el detenerse ante la imagen, decantarla y correlacionar sus signos para advertir en ellos el carácter enunciativo que comportan como huellas, que en este caso debieran ser de una profunda concientización capaz de superar estos estragos y no permitir su repetición.

Cabe advertir, además, la responsabilidad que ostenta esta construcción de sentidos de estas fotografías. En primer término, teniendo en cuenta que las imágenes corresponden a un medio de producción visual a través del cual se crea un rastro visual de legibilidad en un tiempo específico que no es el presente y sin su análisis tampoco puede aseverarse que sea el del pasado, el de la guerra. En este punto debe devolverse la mirada hacia el profesionalismo y civilidad de los fotorreporteros adscritos a la casa editorial El Tiempo debidas cuentas de su deber de cumplimiento con las normativas de sus áreas editoriales en tanto la oportunidad de asistir al evento y la posibilidad del momento para captar la fotografía, aún más, al tipo de enunciación que esta provee y el comentario que la acompaña ya este a distancia del fotorreportero. No obstante, lo cierto es que los lectores al encuentro con esta visualidad construyen imaginarios de una guerra que no han visto y reconocen estimando y tomando criterio en gran medida a partir de lo observado en las fotografías. En suma, son estas las condicionantes de esa idea visual de una particular acción bélica. A propósito, las imágenes que siguen facilitan —-mejor ilustran- algunos de estos aspectos críticos mencionados en cuanto al alcance discursivo de este registro fotográfico y las no pocas y ciertas delimitaciones para su análisis. 


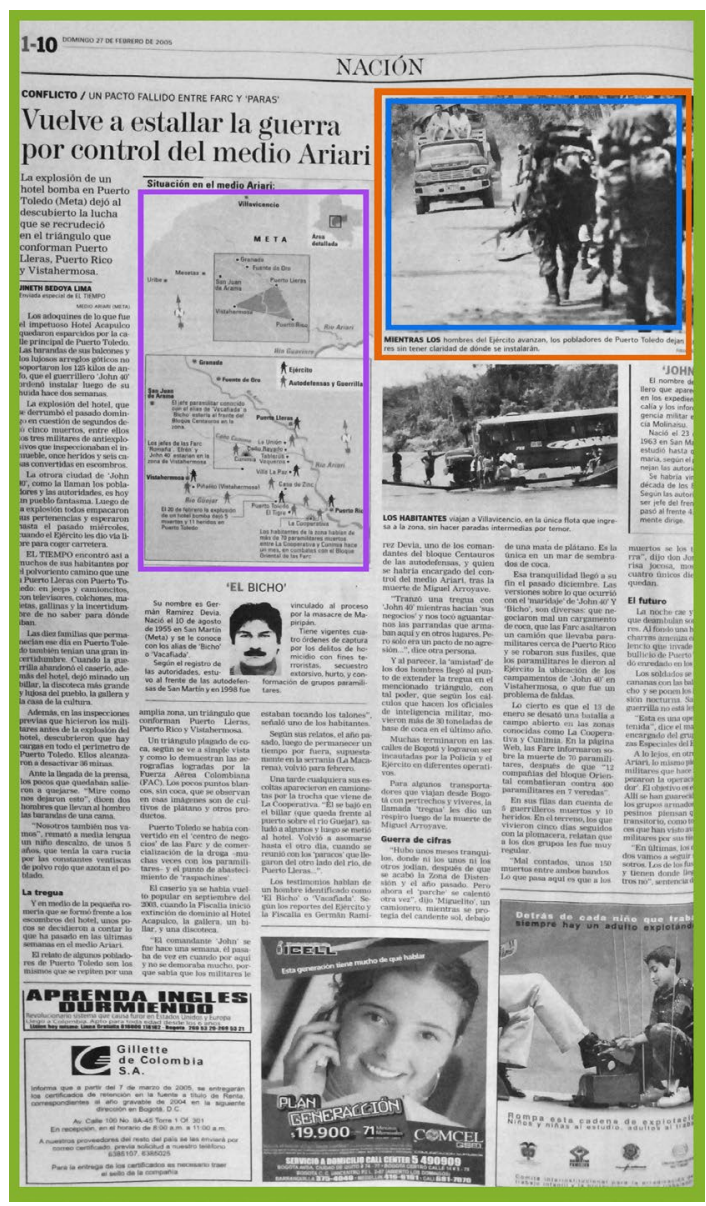

Figura 1. Página completa periódico El Tiempo. Fuente: archivo El Tiempo 2002-2006. 


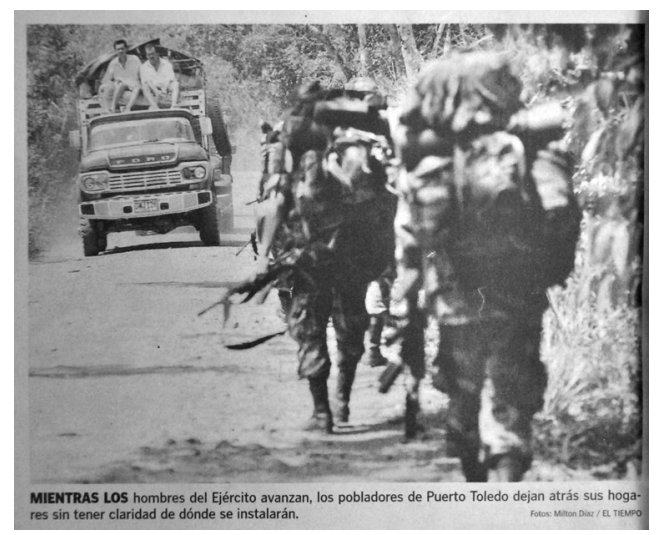

Figura 2. Fotografía con pie de foto. Fuente: archivo El Tiempo 2002-2006.

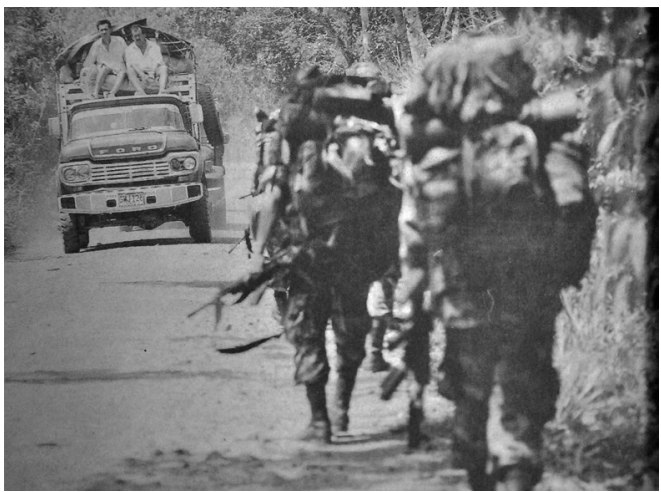

Figura 3. Fotografía en su encuadre original de impresión. Fuente: archivo El Tiempo 2002-2006. 


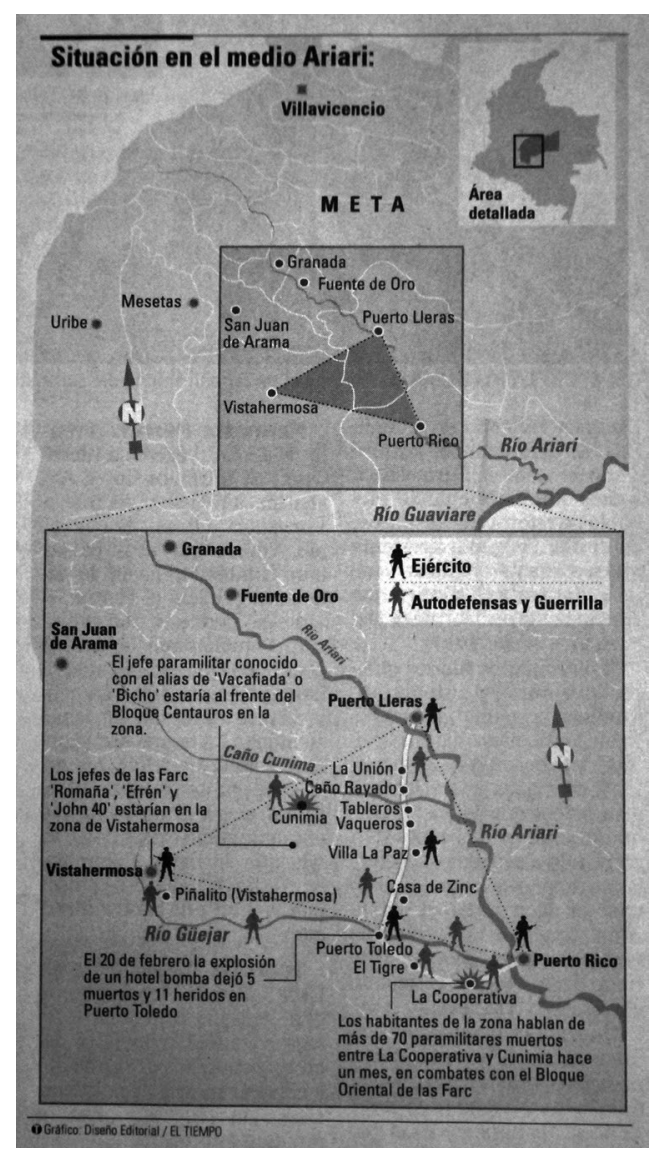

Figura 4. Mapa de información (infografía). Fuente: archivo El Tiempo 2002-2006. 
Si se regresa a la ilustración de la Figura 1, podrá advertirse que el borde de línea verde corresponde a la noticia de un evento concreto que editorialmente se introduce en una página del periódico. Igualmente fíjese que la línea naranja encuadra al evento con un pie de foto, más la línea azul encuadra el original de la impresión. La infografía se señala con línea violeta. Es decir que enfrentar esta fuente de información planteó para los investigadores reconocer un conjunto de estímulos visuales que implicó modos de fragmentación del contenido a informar, configurando una "lógica de visualidad" a través de la lectura y reconocimiento de signos. De tal manera que el fundamento de esta observación se centrará en la imagen fotográfica como ente gráfico visual que en sí mismo declara un carácter enunciativo del fotorreportero. Esta delimitación del material fotorreportero persigue el propósito de describir un valor que conlleva ese acto enunciativo de una realidad (en este caso, de la guerra), pero también la distancia que este puede poseer en relación con lo propuesto desde la connotación editorial de la página completa del periódico.

Plantea Calvino, en relación con la importancia que la tecnología asume en casos como estos, una moción de interés.

Frente al universo de imágenes en que se vive, y por el mismo beneplácito que la tecnología ha legado al trato con las imágenes, la exuberancia de juegos, fantasmagorías y otras tramas, devalúan cada vez más los significados reales, incluso, sin pretender que esos sean copia o espejo de la realidad; pero que tampoco se disuelvan o lean con atención a lo que decida el poder de la publicación. (Calvino, como se citó en Baeza, 2007, p. 9)

En el caso de una fotografía documental, en gran medida producto de un fotoperiodismo guiado por los medios que ejercen el poder de comunicación, en un contexto social ya por demás atribulado y hastiado por los desmanes de la guerra, la prensa responde a razones económicas de control de una inequívoca manera e interviene en los contenidos en ocasiones indirectamente. Sin embargo la connotación de ese soporte editorial resulta uno de los sistemas 
de mayor impacto en la socialización y masificación de la información, por lo que no deja de ser también uno de los instrumentos de mayor fuerza en relación con la memoria histórica documental.

Ahora bien, este repositorio como soporte digital ha de conservar ese total del material fotográfico publicado y su representación constituye una fuente primaria que en tanto base de una colección crea un archivo a modo de fondo documental, memoria y consulta más allá de las problemáticas ya mencionadas sobre la edición. Subsisten también otras nuevas problemáticas de carácter técnico metodológico que ya son propias del repositorio, aunque posibles de depurar con el fin de justipreciar la investigación con un máximo de transparencia y sobre todo por el aporte de esta al rigor inexcusable de toda academia.

Dos ejemplos acerca de estas contrariedades se dan en el cambio de la fotografía de lo analógico a lo digital; que el análisis de la tesis solventó, pero que para el archivo no es fácil advertir y que pudiera afectar su lectura. Por otra parte, el tránsito geopolítico del concepto de revolucionario a terrorista y lo que esto implicó como trasposición de cinco décadas de visualidad; que también afecta a un consultor en su encuentro con rostros y situaciones impensables, funestas. Es decir que el archivo merece de una estimación óptima de fundación y en ese aspecto se adelanta.

Realmente hay un contexto social y político, pero también tecnológico de impacto social que crea visiones de mundo; modelos para un espectador global, pero también para los profesionales del campo visual. Estas imágenes exponen a los actores de la guerra, los cataloga y presenta circunstancialmente al tiempo que evidencian o apuntalan sus características más representativas mediante signos y encuadres acentuando o difuminando sus características originales; pero siempre construyendo modos de ver, modos de presentar la realidad, 
modos de significarla. Se trata de esa impronta y riesgo del fotorreportero que, en el caso de quienes deben de salvaguardar su obra que es única e histórica, representa otro desafío profesional que exige de una superación técnica, de honestidad e inteligencia.

Sentadas las anteriores premisas, la realidad es una y las imágenes construidas por la fotorreportería son una segunda realidad enunciativa que presenta los acontecimientos desde un cierto punto de vista compositivo al reunir ciertos elementos dispersos en el espacio dentro de un encuadre visual que ha de configurar el significado. Este planteamiento se apoya en el pensamiento de Dubois (1986), quien expresa: "con la fotografía ya no nos resulta posible pensar la imagen fuera del acto que la hace posible" (p. 11). De la misma manera, y en este punto, ese acto fotográfico es muy próximo al acto de diseño en cuanto idea o concepto que se elabora en la mente del fotógrafo; instante este que se apresta a la indagación visual en un marco de acción probable de emerger la imagen como fragmento o instante de un acontecimiento que cifra múltiples lecturas.

Ese acto se hace visible en cuanto "sentido y valor de qué y para quién se diseña; de cuál es la comprensión causal de ese acto de diseño" (Horta, 2012, p. 31), acto que imbrica un propósito que puede llegar a la información social o hacia la utilidad social; ambos conceptos convergen en ese sentido de uso, consumo o gusto que apuntalan la razón de ser del diseño desde su responsabilidad social como condición sine qua non. Una vez la fotografía ha sido ideada/diseñada, compuesta, permanece en razón de sus signos como objeto de valor y se dispone como archivo en dirección al proceso de publicación que no se desliga de un contexto social ni del momento histórico al que corresponde con sus diversas variables socioeconómicas y políticas, determinante entonces de una posterior publicación. Pensemos ahora a la luz de estas consideraciones, que la imagen puede ser utilizada para indicar de manera asertiva la naturaleza de 
un acontecimiento desde la fuerza de los signos que encierra o puede llegar a conducirse en cuanto útil o política a trastocar, subvertir o modificar la realidad.

El fotorreportero a través de la lente se dispone ante un instante susceptible de ser registrado, que trasciende en una segunda instancia cuando filtra y conduce el material fotográfico a la editorial —-momento de tensión respecto del lugar que dicha imagen ocupa en atención a la clase de página del rotativo o si simplemente ilustra una sección, y en qué tamaño-, lo que permite advertir que todas las imágenes publicadas en el medio prensa se sintonizan con estas premisas dado que atienden directrices que determinan su valor expositivo con base a intereses varios, incluso no siempre políticos, pero que delimitan la información visual como preponderante o ilustración de un texto quizás que se le ha dado mayor importancia.

Este archivo de memoria histórica documental, más allá de una postura ideoestética del fotorreportero para captar la guerra, da cuenta de una recurrencia estilística estereotipada frente a ciertas narraciones. Para ejemplificar un estereotipo, fíjese en la referencia de las fotografías de laboratorios de droga allanados en las selvas colombianas con una convención gráfico-visual que siempre ubica — en la temporalidad referida - un militar armado para que pose delante de un laboratorio en Ilamas; esto es, una manera reiterada de representar el acontecimiento amén de alguna disposición institucional acerca de la vigilancia del mismo. De los anteriores planteamientos se deduce que, al igual que el formato imagen, el formato prensa incorpora convenciones y modos de ilustrar la información; estableciendo modos de interrelación para comunicar entre contenidos textuales o visuales. Cada imagen reportera publicada impresa se presenta con un ordenamiento visual editorial como estructura comunicativa. Al identificar estos parámetros en relación con la imagen reporteril se identificaron y propusieron modos de abstraer la información para delimitar dichos contenidos ya enunciados anteriormente. 
En otras palabras, las imágenes que aparecen publicadas son editadas con el formato real de captura del fotorreportero en el marco de relaciones que propone el encuadre de la cámara y que difiere de lo publicado por el formato real de impresión del periódico que modifica esta estructura compositiva. Este proceso adopta otras intenciones de publicación que ya dependen de las directrices hegemónicas, políticas y económicas del medio, diferenciando el registro original del fotorreportero de aquel que se publica. Un ejemplo puede ser el siguiente.

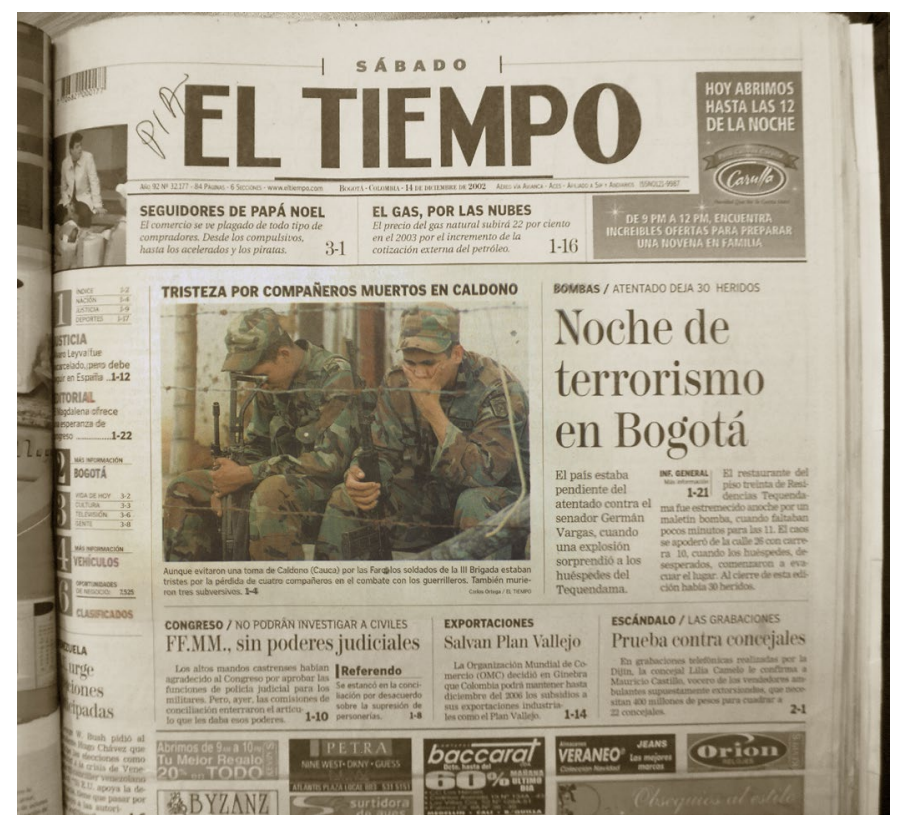

Figura 5. Página contexto de la noticia publicada en el diario de circulación nacional El Tiempo. Fuente: archivo El Tiempo 2002-2006. 


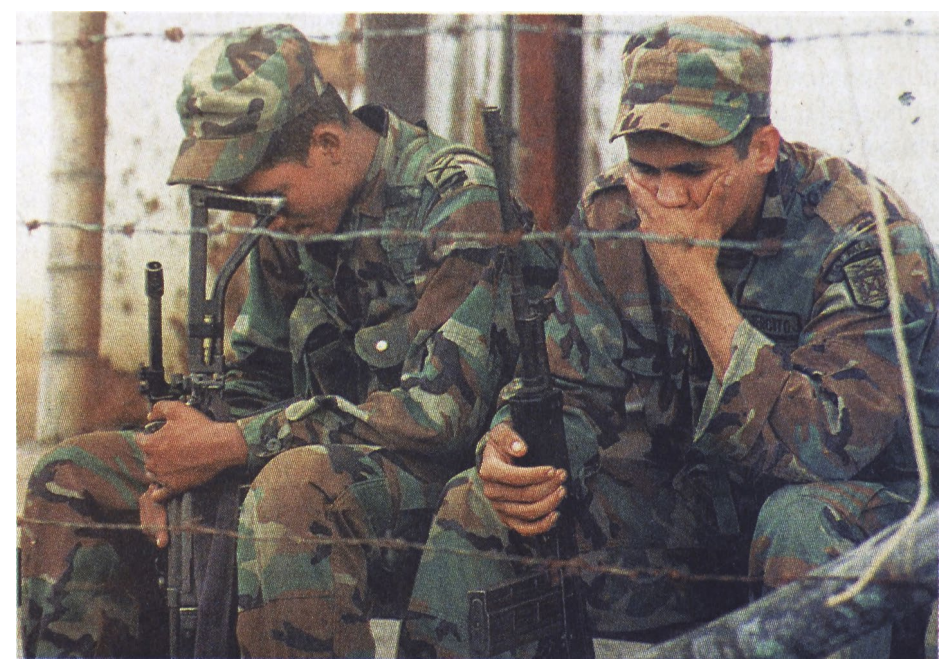

Figura 6. Fotografía en su encuadre original de impresión editada por la editorial para su publicación. Titular: "Tristeza por compañeros muertos en Caldono". Pie de foto: aunque evitaron una toma de Caldono (Cauca) por las FARC los soldados de la III Brigada estaban

tristes por la pérdida de cuatro de sus compañeros en el combate con los guerrilleros.

También murieron tres subversivos. Carlos Ortega, El Tiempo, 14 de diciembre de 2002. Fuente: archivo El Tiempo 2002-2006.

Este caso habla de la imagen publicada por la prensa nacional El Tiempo, imagen que se presenta en un plano cerrado que recoge la actitud de dos soldados impactados por la noticia de varios de sus compañeros muertos en una confrontación armada; podría pensarse que este modo de encuadrar la realidad se constituye en un registro construido por el fotorreportero en el que dicho profesional de la imagen cierra el encuadre sobre las expresiones de los soldados para precisar a través de su corporeidad y gestualidad el impacto de los acontecimientos. En atención a diferenciar entre lo fotografiado y lo presentado por el medio en la edición impresa se indagó por otras fuentes para ubicar si esta imagen era o no la fotografía original tomada en terreno. El resultado, se presenta a continuación. 


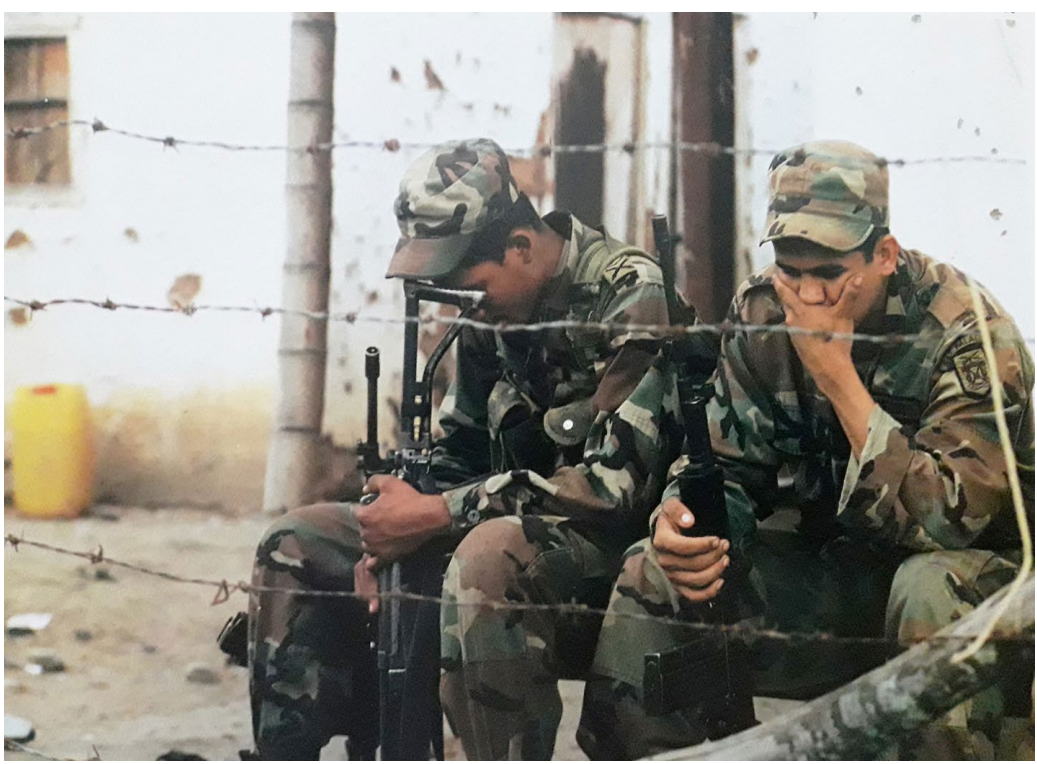

Figura 7. Fotografía en su encuadre compositivo original publicada en revista. Titular: "Colombia

a través del Tiempo 2003". Pie de foto: el quinto intento de la guerrilla en menos de tres años por tomarse la población de Caldono, Cauca, fracasó gracias a la intervención de una base de emergencia

de la III Brigada del Ejército. Los cuatro intentos anteriores fueron repelidos por los pobladores desarmados, modelo de resistencia civil en el país. Dos soldados de la III Brigada lloran la pérdida de cuatro de sus compañeros caídos en el combate. Carlos Ortega, El Tiempo, 14 de diciembre de 2002. Fuente: archivo El Tiempo 2002-2006. 

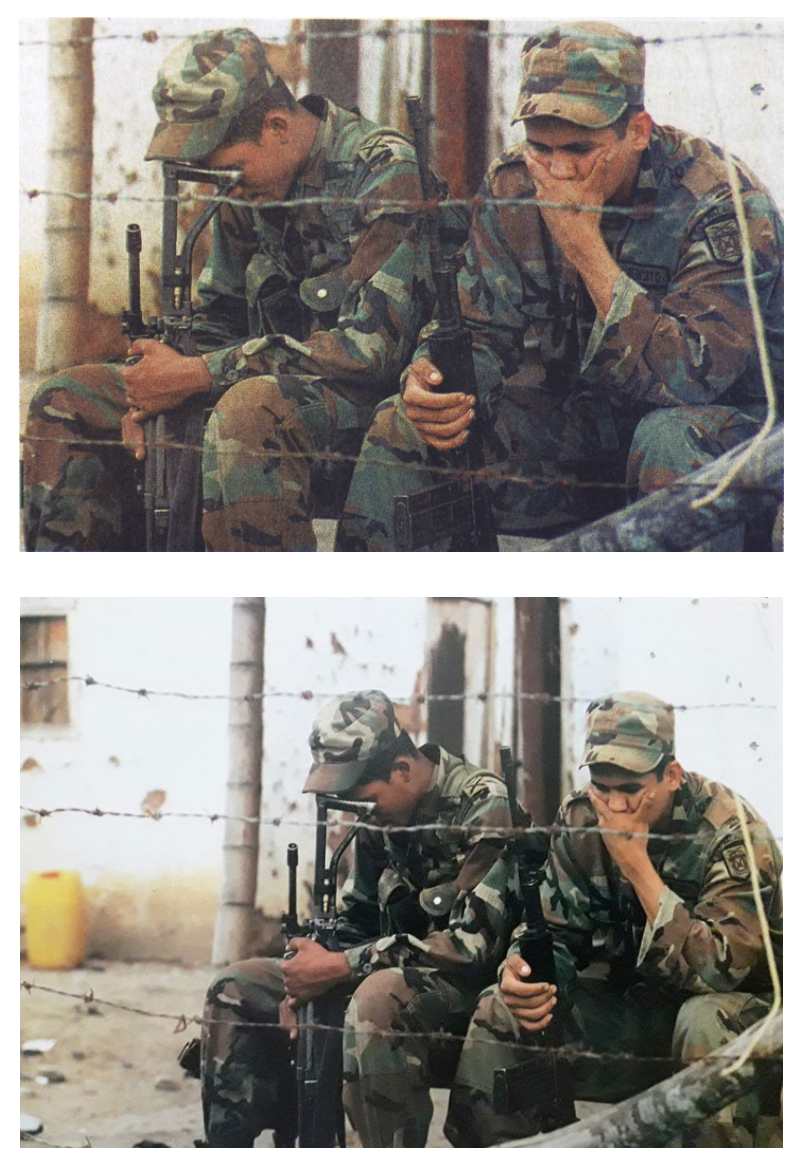

Figura 8. Comparativo gráfico visual del encuadre compositivo. Imagen editada e imagen original impresa en soportes editoriales diferentes. Fuente: archivo El Tiempo 2002-2006. 
En suma, estas dos fotografías (Figura 8) permiten comprender la diferencia de perspectiva entre las dos visiones de lo contruido por la editorial y consecutivamente la anomalia que ello representa en tanto la imagen original propone otras construcciones de sentido.

Esta triada visual y el orden en que se catalogó y etiquetó cada imagen, son instrumentos que ofrecen un panorama concreto sobre el cual orientarse en el repositorio visual. Al cabo, tablero virtual fotográfico construido por la fotorreportería aleatoriamente que pone en evidencia el ejercicio profesional y editorial mediante la selección de un material publicado; un banco que es en sí mismo testimonio de los hechos considerados relevantes de la guerra en un período de alta complejidad que permite señalar las políticas y directrices nacionales e internacionales que influyeron en Colombia entre 2002-2006, así como en respuesta a la política de paz del gobierno Pastrana (1998-2002). Al respecto, André Porto López (2011) planteaba acerca del documento imagen una reflexión de valor importante:

los documentos imagéticos de archivos suelen producir la organización individualizada de unidades documentales o, en la mejor de las hipótesis, la formación de colecciones disociadas de su organismo productor, reduciendo de este modo las posibilidades de una comprensión global de su significado. (p. 4)

Una notación singular debiera acotarse sobre este archivo fotorreportero del repositorio. Estas imágenes corresponden a un conflicto armado de cinco décadas en Colombia, siendo una memoria documental; aunque ese mismo período de la investigación coincide con un giro extremo de política internacional dado por los lineamientos estadounidenses sobre cómo combatir la guerra reconfigurados a partir de los acontecimientos de destrucción de las torres gemelas en 2001, lo que desató una ideología sustentada en la connotación de un concepto desde entonces polivante: el terrorismo. 
Este acontecimiento, junto el tránsito de lo analógico a lo digital, no solo plantea la sustancial transformación de los contextos, sino que advierte un giro tecnológico y una nueva lógica de lo visual. Es de resaltar como este cambio de producir la imagen impacta a la población de manera positiva y favorece a la administración del Estado, ya que la imagen constituye uno de los referentes de más contundencia para difundir logros y también tragedias. Dígase que la sociedad colombiana en general considera este período como un tiempo de calma, justo cuando era más feroz el impacto de la guerra. Este planteamiento se confirma en el caso de que lo construido visualmente y publicado del conflicto a través de las imágenes de los medios, lo que destacaba era el pie de fuerza presente en las vías en los diferentes territorios otrora territorios guerrilleros; es decir la creación de un imaginario de seguridad soportado por la presencia armada del Estado y descrito a través de las imágenes como calma y control de la seguridad ciudadana. Un paradigma complejo y difícil en cuanto esa misma manifestación de fuerza significó una guerra exacerbada que no apareció literalmente en los medios. Pero que sí son visibles en el informe ¡Basta Ya! del Centro Nacional de Memoria Histórica (CNMH), lo que indica una diferencia esencial entre el acontecimiento y la manera en cómo se ilustró.

Ante una geopolítica contra el terrorismo, la Nación exhibió una campaña muy fuerte que atendía la injerencia internacional directa sobre los presupuestos para la guerra y para su proyectado exterminio; aspectos que evidencian un panorama de calma cuando es más cruda la realidad de la guerra. Ese imaginario viene siendo uno de los aspectos que evidencia esta investigación en cuanto advierte socioculturalmente una transformación a partir de los modos en que se enuncia la realidad desde unos imperativos internacionales que eventualmente difieren de las connotaciones contextuales de la guerra en nuestro país; y que inciden progresivamente en la delimitación visual que se hace de los eventos susceptibles de ser registrados por la fotorreportería. 
Por otro lado es importante cómo este banco de imágenes resultó como pretexto para un ejercicio de análisis acerca de archivos de esta clase a modo de permitir a los usuarios un sitio de entrenamiento de la mirada del investigador, de rigor en la observación e interpretación de los signos que una guerra presenta, aun con las consabidas afectaciones que puedan generarse por parte de su edición y publicación. De igual manera este repositorio representa un fondo de valor en la construcción de una plataforma que custodia el archivo de una fotorreportería bajo el principio de que su estructura, funcionalidad y categorías de clasificación advierten con dos anexos de imágenes: la comparación entre el conflicto armado en Colombia y los eventos de guerra a nivel internacional, en donde se hace posible reflexionar en el cómo y el contenido de esa enunciación propuesto por los fotógrafos desde diferentes geografías y que posibilita contrastar los acontecimientos en cadena con una visualidad de cuatro años.

Este archivo de imágenes en tanto estructura, contenido y soporte visual asume el carácter de un documento, de un texto cultural de memoria acerca de lo infructuoso de una guerra que superó cinco décadas de existencia. Un archivo, citando a Carmen María Jaramillo (2010), que posee la misión de mostrar "las posibles narrativas y 'verdades' que se construyen, destruyen o manipulan a partir de su uso" (p. 15). En este sentido el repositorio se constituye como herramienta de análisis y memoria de un espacio-tiempo que, dejando tantas falencias, traumatismos sociales y desprotección, puede y debe alertar como una lección época de la cultura colombiana.

\section{Conclusiones}

Llegar a un balance crítico sobre la concepción y montaje de una metodología de investigación, pareciera poco factible; sin embargo puede ser útil destacar qué aspectos tuvieron una marcada dificultad, teniendo en cuenta que se trataba de la creación de un archivo de fotorreportería. Aunque la codificación 
de la imagen fotográfica se ganó la primera experiencia, quizás por lo no pensado o inesperado de conocer el código originario que otorga la cámara en su conteo al reiniciarse en los diferentes momentos de captura y en cómo diferenciar esto en un complexo temporal de cuatro años. Hallar la precisión de este dato significó, considerando el valor del tiempo en una investigación, un gran esfuerzo que sobrepasa lo técnico inteligible y exige de constancia para mantener cada etapa diferenciada hasta llegar al archivo que se consolidó en el formato digital definido en el repositorio.

No menos tensional significó el sensibilizar al personal involucrado tangencialmente en los procesos de estandarización de formatos, codificación y ajuste digital dada la exacerbación de lo bélico en algunos apartados tales como masacres, desaparición forzada, fosas comunes entre otras categorías consideradas, implicando que algunos involucrados desistieran de continuar con el trabajo dado el impacto visual del material, cuestión que definía el iniciar de nuevo el proceso con nuevos colaboradores.

Un tercer aspecto igual de complicado fue garantizar el capital humano en la administración del servidor, validar las claves, mantener los pagos y los protocolos para la optimización, subida y fichaje del material. En ello es pertinente expresar el proceso en sus mínimas acepciones en procura de garantizar su sustentabilidad y progresión en el tiempo, aunque entendiendo que los funcionarios y técnicos pasan mientras las organizaciones permanecen y la academia atesora. A esto se suma el rediseño constante que exige el home, el que frente a los públicos con los cuales dialoga debe ir incorporando nuevas lógicas de visualidad y el dato en procesos que posiblemente deban sumarse dadas las condicionantes de interacción con usuarios especializados.

En definitiva, el repositorio constituye en su constructo un catálogo especial que permite desde diferentes perspectivas disciplinares el abordaje metodológico 
propuesto para así ampliar el espectro de conocimiento sobre este campo de la visualidad del fenómeno imagen de la guerra en las cinco décadas tratadas por la fotorreportería del conflicto armado colombiano entre 2002-2006; más aún, como posibilidad para enfrentar temporalidades de guerra de otras geografías y conflictos registrados por la acción reporteril y reflexionar sobre un presente de construcción de paz sostenible. Los hallazgos de la investigación y su montaje exponen un ejercicio metodológico en cuanto pensar, investigar y tratar con una fuente primaria tan compleja como la fotorreportería.

El repositorio digital Centro de Documentación especializado Imagoteca de la Universidad de Caldas, constituye en tanto investigación pública académica un antecedente de memoria visual para la exploración de un "Nodo Latinoamericano de Fotografía del Conflicto Armado" con vista al estudio, investigación y consulta con posibilidades de intervención lineal, comparada, de búsqueda de subtextos y otras incursiones temáticas colindantes. En este sentido la investigación muestra en su interfaz una correcta visualización en cuanto al ordenamiento gráfico-visual del material y su correlación con las etiquetas articuladas a los tesauros. Cabe advertir que una etapa actual de la investigación prueba la correspondencia entre el diseño de información, los datos, la interfaz y la interacción del usuario para cimentar la estructura teórico-conceptual de visualización en tanto memoria histórica.

Finalmente vale la pena acotar que esta antesala visual como memoria de la guerra se fundamenta por un solo medio de prensa de los varios de circulación nacional, en este caso el periódico El Tiempo, por lo cual podría constituir un estímulo para la investigación explorar algunos de estos temas ya enunciados con el levantamiento de otros órganos de prensa y continuar la configuración de otros archivos de valiosa contribución en este tiempo de transición y posconflicto. Así pues, habría de estimarse con prontitud qué estrategias seguir respecto de las temporalidades y actos de memoria no reconocidos. De igual 
modo las categorías consideradas en este estudio ya responden a un pasado de conflicto; aunque probablemente surgirán otras alternativas que expliquen entonces cuál es el tiempo que se quiere vivir, dónde está la civilidad y qué conflicto puede o no obviar las armas. En fin, ¿qué significa no estar de acuerdo, pero sí en paz?

\section{Referencias}

Baeza, P. (2007). Por una función crítica de la fotografía de prensa. Barcelona, España: Gustavo Gilli.

Benveniste, É. (1999). Problemas de lingüística general. Ciudad de México, México: Siglo XXI Editores.

Colombres, A. (2012). La descolonización de la mirada. Una introducción a la antropología visual. La Habana, Cuba: Instituto Cubano del Arte e Industria Cinematográficos.

Claramonte, J. (2016). Estética modal. Madrid, España: Tecnos.

Didi-Huberman, G. (2004). Imágenes pese a todo: memoria visual del holocausto. Barcelona, España: Paidós.

Dubois, P. (1986). El acto fotográfico. Barcelona, España: Paidós.

Giunta, A. (2010). Archivos. Políticas del conocimiento en el arte de América Latina. Revista de Artes Visuales. ERRATA \#, 1, 20-37.

Horta, A. (2012). Trazos poéticos del diseño. Manizales, Colombia: Universidad de Caldas.

Jaramillo, C. (2010). Archivos y política/políticas de archivo. Revista de Artes Visuales. ERRATA \#, 1, 14-19. 
López, A.P. (2011). Contextualización archivística de documentos fotográficos. Alexandria, 5 (8), 3-16.

Mitchell, W.J.T. (2009). Teoría de la imagen. Ensayos sobre representación verbal y visual. Madrid, España: Akal.

Morawski, S. (1999). Fundamentos de estética. Barcelona, España: Ediciones Península.

Ospina, W. (1995). Colombia, el proyecto nacional y la franja amarilla. Barcelona, España: Mondadori.

Sixirei, C. (2012). La violencia en Colombia (1990-2002). Antecedentes y desarrollo histórico. Vigo, España: Universidad de Vigo.

Vásquez, T. (2015). Territorios, conflicto armado y política en el Caquetá: 19002010. Bogotá, Colombia: Universidad de los Andes.

Zunzunegui, S. (1995). Pensar la imagen. Madrid, España: Cátedra.

Como citar: Herrera Murcia, J.W. et al. (2019). Apuntes metodológicos para la creación de un archivo digital sobre la fotografía del conflicto armado en Colombia 2002-2006. Revista KEPES, 16 (19), 183-216. DOI: 10.17151/kepes.2019.16.19.8 